\title{
Optimized design guideline of battery-cell equalizers based on the wave-trap concept
}

\author{
M. Arias, J. Sebastián, M.M. Hernando, A. Vázquez \\ University of Oviedo. Campus de Viesques s/n \\ Gijón 33204 SPAIN \\ mail: ariasmanuel@uniovi.es
}

\begin{abstract}
Active equalizers, with a higher efficiency in comparison to passive ones, have the disadvantage of using a considerable number of components. The wave-trap concept allows the battery cell equalizer to use its switching frequency as the control variable that decides which cell is being charged. Hence, the number of controlled switches is strongly reduced without reducing the performance of the system. In this paper, an optimized design guideline for an equalizer based on this concept is presented. First, the mathematical equations that describe the behavior of each trap are introduced. Then, these equations are used for calculating the optimum value of all the parameters of the system. This optimum calculation is based on relating the injected energy in the battery cell and the resonant energy of the chosen trap. This design guideline has been used in the development of a 4-battery-cell equalizer based on a half-bridge structure.
\end{abstract}

Keywords: battery, cell, equalizer, balancing, wave trap, frequency.

\section{INTRODUCTION}

Equalizers are needed in order to assure that all the cells connected in series are fully charged even when they have small differences in the capacity. In this way, the energy stored in the battery is maximized without damaging any of the cells. Equalizers can be classified in passive and active equalizers [1], [2]. The first ones are based in dissipative methods, in which the excess of energy is removed from fully-charged cells while the rest of the cells are still being charged [3], [4]. The cost of this kind of equalizers is the lowest one and the control scheme is simple. Nevertheless, the efficiency is considerably low due to the amount of dissipated energy. Moreover, the number of elements is not necessarily low.

Active equalizers, on the other hand, present the highest efficiency as they are based on transferring energy from one element (cell pack or most-charged cell) to another element (most discharged cell or cell pack) until all the cells reach the fully-charged state. This transference can be achieved in several ways. One option is using capacitors [4] or inductors [5] for storing the energy extracted from one element (e.g., the most-charged cell or the cell pack) and transferring it to another element (e.g., the most-discharged cell). Another option is using converters which directly transfer the energy between cells and balance them [6]. In all the cases, the number of components is extremely high. Besides, its cost is higher than the cost of passive solutions.

This work has been supported by the Spanish Government under projects CONSOLIDER MICINN-10-CSD2009-00046 and ANRI-DOC (DPI201347176-C2-2-R), by European Union under project SPEED (FP7-NMP3-LA2013-604057) and by IKERLAN and ORONA under project FUO-EM-072-

\author{
U. Viscarret \\ Ikerlan; \\ $\mathrm{P}^{\mathrm{o}}$ J. M. Arizmendiarrieta, 20500 \\ Arrasate-Mondragón (Gipuzkoa)
}

In [7], the wave-trap concept is proposed as a possible option for reducing the number of controlled switches used in an equalizer. The switching frequency (not a complex array of controlled switches) is used for determining which cell is going to receive the extra energy provided by the equalizer. Nevertheless, [7] only proved the validity of the idea, but did not present a detailed design guideline. In this paper, this guideline is developed. It is based on the mathematical equations that described the behavior of a trap and in the ratio resonant energy-transferred energy. Also, components' tolerances are taken into account.

This paper is organized as follows. A brief description of the proposed concept is provided in section II. A deep insight of the topology is given in section III. The design guideline resulting from the previous sections is explained in section IV. Finally, the experimental results are shown in section V and the conclusions are gathered in section VI.

\section{BRIEF DESCRIPTION OF THE PROPOSED CONCEPT}

The purpose of this section is providing a brief description of the wave-trap concept proposed in [7] in order to ease the understanding of the following sections.

In Fig. 1a, a string of $\mathrm{n}$ traps is presented. Each trap consists of a capacitor and an inductor connected in parallel. Therefore, the impedance of each trap is:

$$
Z_{i}(\omega)=\frac{j \cdot \omega \cdot L_{i}}{1-\omega^{2} \cdot L_{i} \cdot C_{i}},
$$

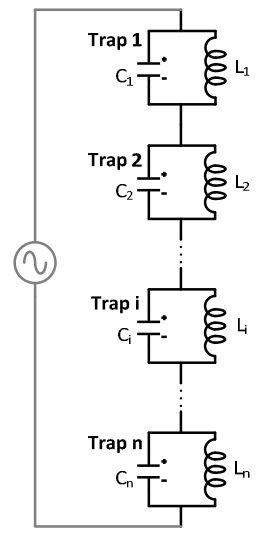

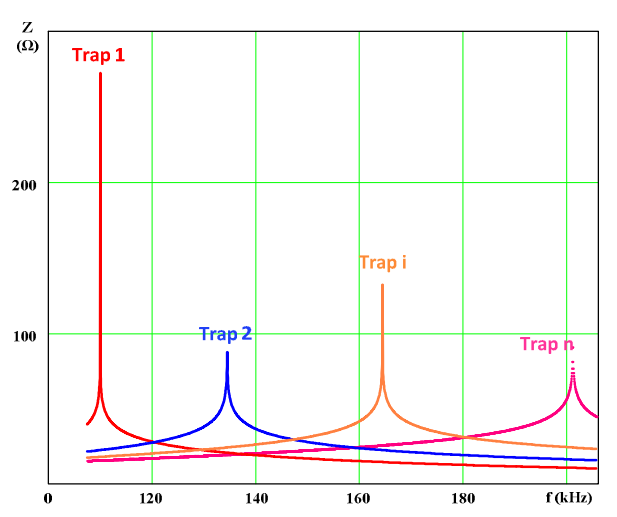

b)

Fig. 1. a) String of $n$ traps (in grey, a sinusoidal voltage source); b) Impedance of the $\mathrm{n}$ traps as a function of the frequency of the sinusoidal voltage applied to the string. 
where $Z_{i}(\omega)$ is the impedance of trap i for the pulsation $\omega$, and $\mathrm{L}_{\mathrm{i}}$ and $\mathrm{C}_{\mathrm{i}}$ are the inductance and the capacitance of the inductor and the capacitor used in the trap. The resonant frequency $f_{i}$ of trap $i$ is:

$$
f_{i}=\frac{1}{2 \cdot \pi \cdot \sqrt{L_{i} \cdot C_{i}}}
$$

Each trap is designed so that its resonant frequency is different from the resonant frequencies of the other traps (Fig. 1b). If this string of traps is supplied with a sinusoidal voltage whose frequency is equal to the resonant frequency of one of the traps, according to (1) its impedance will be considerably higher than the impedance of the other traps (Fig. 1b). Consequently, nearly all the voltage applied to the string will be withstood by this trap. It is possible to take advantage of this concept and use it for a battery equalizer by employing a circuit as the one proposed in Fig. $2 \mathrm{a}$.

\section{ANALYSIS OF THE TOPOLOGY}

For the sake of simplicity, only the first harmonic component $\left(\mathrm{V}_{\left.\mathrm{HB}_{\mathrm{H} 1}\right)}\right.$ of the voltage provided by the halfbridge structure $\left(\overline{\mathrm{V}}_{\mathrm{HB}}\right)$ will be considered [8]-[10].

The Fourier analysis of $\mathrm{V}_{\mathrm{HB}}$ in Fig. 2a. leads to the following equation:

$$
\mathrm{V}_{\mathrm{HB}_{-} \mathrm{h} 1}(\mathrm{t})=\mathrm{A}_{\mathrm{h} 1}\left(\mathrm{D}, \mathrm{V}_{\mathrm{in}}\right) \cdot \sin \left(2 \cdot \pi \cdot \mathrm{f}_{\mathrm{sw}} \cdot \mathrm{t}+\Phi_{\mathrm{sw}}\right),
$$

where:

$$
\begin{gathered}
\mathrm{A}_{\mathrm{h} 1}\left(\mathrm{D}, \mathrm{V}_{\mathrm{in}}\right)=\frac{2 \cdot \mathrm{V}_{\mathrm{in}}}{\pi} \cdot \sin (\pi \cdot \mathrm{D}), \\
\Phi_{\mathrm{sw}}=\pi \cdot\left(\frac{1-2 \cdot \mathrm{D}}{2}\right)
\end{gathered}
$$

$\mathrm{D}$ is the duty cycle of MOSFET $\mathrm{M}_{1}$, and $\mathrm{V}_{\text {in }}$ is the input voltage of the half-bridge structure.

The half-bridge structure will always operate with a switching frequency $f_{\text {sw }}$ equal to the resonant frequency $f_{i}$ of one of the traps. Therefore, the voltage withstood by the chosen trap $\mathrm{V}_{\text {Trap__}}(\mathrm{t})$ can be approached by $\mathrm{V}_{\mathrm{HB}_{-} \mathrm{h} 1}(\mathrm{t})$ :

$$
\mathrm{V}_{\text {Trap }_{-} \mathrm{i}}(\mathrm{t}) \approx \mathrm{V}_{\mathrm{HB}_{-} \mathrm{h} 1}(\mathrm{t})=\mathrm{A}_{\mathrm{h} 1}\left(\mathrm{D}, \mathrm{V}_{\mathrm{in}}\right) \cdot \sin \left(2 \cdot \pi \cdot \mathrm{f}_{\mathrm{i}} \cdot \mathrm{t}+\Phi_{\mathrm{i}}\right) \text {. }
$$

Equations (4) and (6) show that the amplitude of $\mathrm{v}_{\text {Trap }}{ }_{\mathrm{i}}(\mathrm{t})$ can be controlled by means of the duty cycle D.

The chosen trap shown in Fig. $2 b$ has been redrawn in Fig. 3a. In this figure, the capacitor $\mathrm{C}_{\mathrm{i}}$ has been replaced with the voltage source $v_{\text {Trap }}$ i $(t)$ due to the high quality factor of the filter that each trap represents. The behavior of the trap will change depending on whether the diode is reverse biased

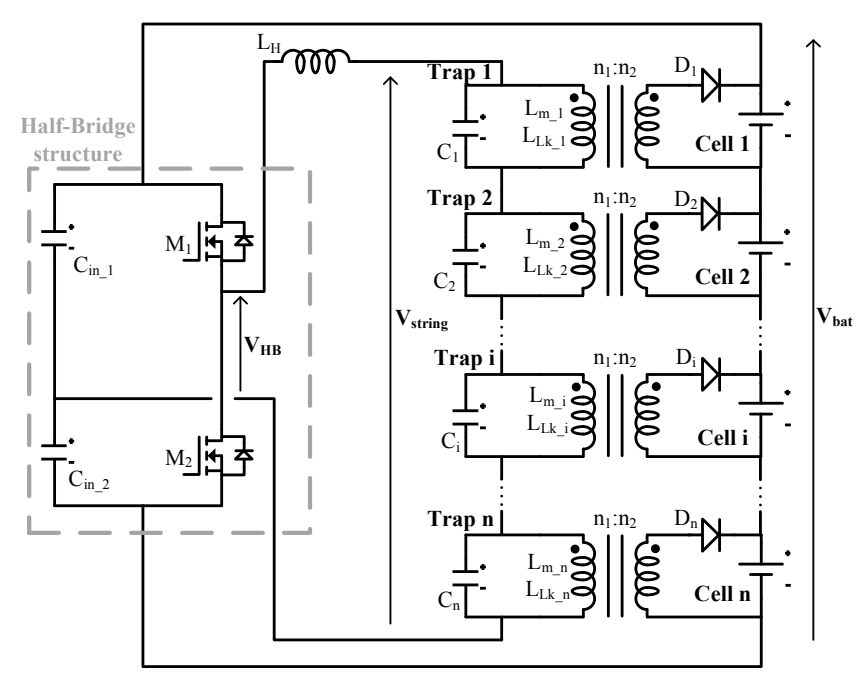

a)

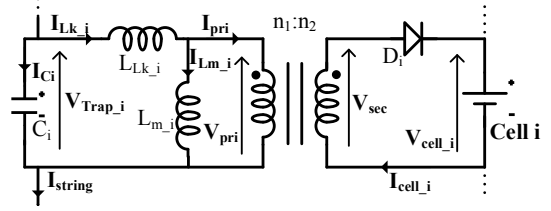

b)

Fig. 2. a) Scheme of the proposed battery equalizer; b) Detail of trap $i$ including the leakage and the magnetizing inductances of the transformer.

or not. When it is reverse biased, the valid circuit is the one presented in Fig. 3b. When it is directly biased the trap will behave as the circuit presented in Fig. 3c. With these two circuits it is possible to calculate the electric charge that the trap transfers to the cell in each switching period.

For the sake of clarity, in the next explanation $v_{\text {Trap }}{ }_{i}(t)$ will be referred to t', a different time reference. Equation (6) can be rewritten as:

$$
\mathrm{v}_{\text {Trap }_{-} \mathrm{i}}\left(\mathrm{t}^{\prime}\right)=\mathrm{A}_{\mathrm{h} 1}\left(\mathrm{D}, \mathrm{V}_{\mathrm{in}}\right) \cdot \sin \left(2 \cdot \pi \cdot \mathrm{f}_{\mathrm{i}} \cdot \mathrm{t}^{\prime}\right),
$$

where t' is:

$$
\mathrm{t}^{\prime}=\mathrm{t}+\frac{\Phi_{\mathrm{i}}}{2 \cdot \pi \cdot \mathrm{f}_{\mathrm{i}}}
$$

When the diode is not directly biased (Fig. 3b), the current through the magnetizing inductance is equal to the current through the leakage inductance. This current can be calculated using the sinusoidal steady-state phasor analysis because the diode conduction time is much shorter that the resonant period. Therefore:

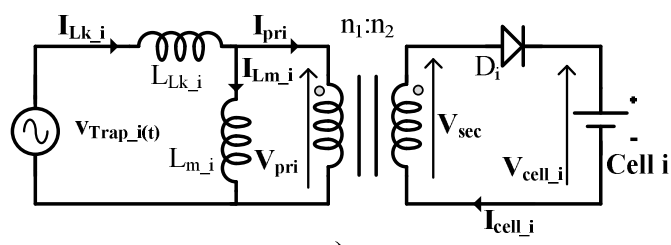

a)

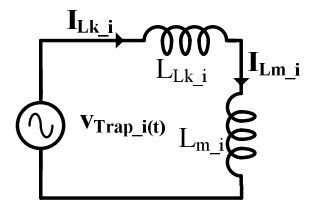

b)

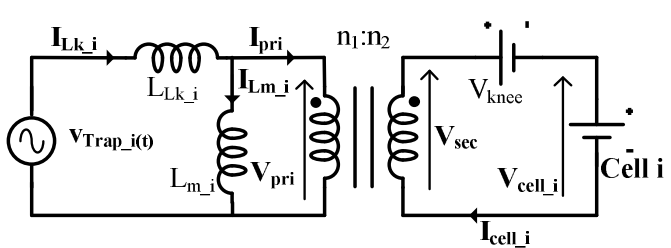

Fig. 3. a) Equivalent circuit of the trap; b) when the diode is reverse biased; c) when the diode is directly biased 


$$
\begin{aligned}
\mathrm{i}_{\mathrm{Lm}_{-} \mathrm{i}}\left(\mathrm{t}^{\prime}\right) & =\mathrm{i}_{\mathrm{Lk}_{-} \mathrm{i}}\left(\mathrm{t}^{\prime}\right)=\frac{\mathrm{v}_{\text {Trap } \__{-} \mathrm{i}}\left(\mathrm{t}^{\prime}\right)}{\mathrm{j} \cdot 2 \cdot \pi \cdot \mathrm{f}_{\mathrm{i}} \cdot \mathrm{L}_{\mathrm{i}}}= \\
& =\frac{1}{2 \cdot \pi \cdot \mathrm{f}_{\mathrm{i}} \cdot \mathrm{L}_{\mathrm{i}}} \cdot \mathrm{A}_{\mathrm{h} 1}\left(\mathrm{D}, \mathrm{V}_{\text {in }}\right) \cdot \sin \left(2 \cdot \pi \cdot \mathrm{f}_{\mathrm{i}} \cdot \mathrm{t}^{\prime}-\frac{\pi}{2}\right),
\end{aligned}
$$

where:

$$
\mathrm{L}_{\mathrm{i}}=\mathrm{L}_{\mathrm{Lk}_{-} \mathrm{i}}+\mathrm{L}_{\mathrm{m}_{-} \mathrm{i}} \text {. }
$$

In the same way, the current through the capacitor of the trap is:

$$
\begin{aligned}
\mathrm{i}_{\mathrm{Ci}}\left(\mathrm{t}^{\prime}\right) & =\mathrm{j} \cdot 2 \cdot \pi \cdot \mathrm{f}_{\mathrm{i}} \cdot \mathrm{C}_{\mathrm{i}} \cdot \mathrm{v}_{\text {Trap_i } \mathrm{i}_{-} 1}\left(\mathrm{t}^{\prime}\right)= \\
& =2 \cdot \pi \cdot \mathrm{f}_{\mathrm{i}} \cdot \mathrm{C}_{\mathrm{i}} \cdot \mathrm{A}_{\mathrm{h} 1}\left(\mathrm{D}, \mathrm{V}_{\text {in }}\right) \cdot \sin \left(2 \cdot \pi \cdot \mathrm{f}_{\mathrm{i}} \cdot \mathrm{t}^{\prime}+\frac{\pi}{2}\right) .
\end{aligned}
$$

Both currents have been represented in Fig. $4 \mathrm{a}$.

The diode will be directly biased at $\mathrm{t}_{\text {ch_ini: }}$ :

$$
\begin{aligned}
\mathrm{t}_{\text {ch_ini }}^{\prime}= & \frac{1}{2 \cdot \pi \cdot \mathrm{f}_{\mathrm{i}}} \cdot \\
& \cdot \operatorname{asin}\left(\frac{\mathrm{V}_{\text {cell_i } \mathrm{i}}+\mathrm{V}_{\text {knee }}}{\mathrm{r}_{\mathrm{tr}_{-} \mathrm{i}}} \cdot \frac{\mathrm{L}_{\mathrm{i}}}{\mathrm{L}_{\mathrm{m}_{-} \mathrm{i}}} \cdot \frac{\pi}{2 \cdot \mathrm{V}_{\text {in }} \cdot \sin (\pi \cdot \mathrm{D})}\right) .
\end{aligned}
$$

When the diode is directly biased, the valid circuit is Fig. $3 \mathrm{c}$. Therefore, the current injected into the chosen cell is:

$$
\mathrm{i}_{\text {cell_ } \mathrm{i}^{\mathrm{i}}}\left(\mathrm{t}^{\prime}\right)=\frac{1}{\mathrm{r}_{\mathrm{tr} \_\mathrm{i}}}\left(\mathrm{i}_{\mathrm{Lk}_{-} \mathrm{i}}\left(\mathrm{t}^{\prime}\right)-\mathrm{i}_{\mathrm{Lm}_{-} \mathrm{i}}\left(\mathrm{t}^{\prime}\right)\right)
$$

Taking into account that $\mathrm{i}_{\mathrm{Lm}_{-} \mathrm{i}}\left(\mathrm{t}^{\prime}{ }_{\text {ch_ini }}\right)=\mathrm{i}_{\mathrm{Lk}_{-} \mathrm{i}}\left(\mathrm{t}{ }_{\text {ch_ini }}\right)$, becomes:

$$
\begin{aligned}
& \mathrm{i}_{\text {cell_i }}\left(\mathrm{t}^{\prime}\right)=
\end{aligned}
$$

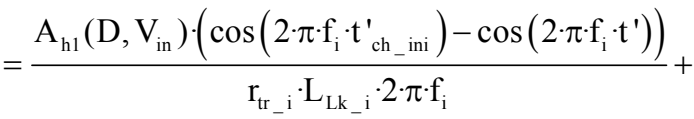

$$
\begin{aligned}
& +\frac{\left(\mathrm{V}_{\text {cell_ } \mathrm{i}}+\mathrm{V}_{\mathrm{knee}}\right) \cdot\left(\mathrm{t}_{{ }_{\text {ch_ini }}}-\mathrm{t}^{\prime}\right)}{\mathrm{r}_{\mathrm{tr} \_}^{2} \mathrm{i}} \cdot\left(\frac{1}{\mathrm{~L}_{\mathrm{Lk}_{-} \mathrm{i}}}+\frac{1}{\mathrm{~L}_{\mathrm{m}_{-} \mathrm{i}}}\right)
\end{aligned}
$$

The diode will be directly biased until the current injected into the cell becomes zero, at $\mathrm{t}_{\text {ch end }}$ :

$$
\mathrm{i}_{\text {cell_i }}\left(\mathrm{t}_{\text {ch_end }_{\text {end }}}\right)=0
$$

Finally, the average current injected into the chosen battery cell can be calculated very easily:

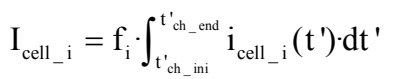

where $I_{\text {cell i }}$ denotes the average value of the current injected into the battery cell.

The current injected into the cell should be controlled in order to be able to precisely define the final voltage of the cell. As can be seen in (14), the current injected into the cell depends on the amplitude of the first harmonic component of the voltage withstood by the trap $\left(A_{h 1}\left(D, V_{i n}\right)\right)$ and, therefore, on the duty cycle $\mathrm{D}$. As a consequence, the proposed equalizer can control the amount of energy injected into the cell during each switching period.

The maximum value of the current $i_{\text {cell_ }}\left(t^{\prime}\right)$, given in equation (14), corresponds to the maximum value of $A_{h 1}\left(D, V_{\text {in }}\right)$, which takes place when $D=0.5$. Therefore,

$$
\begin{aligned}
& \mathrm{i}_{\text {cell___max }}\left(\mathrm{t}^{\prime}\right)= \\
& =\frac{\mathrm{V}_{\text {in }} \cdot\left(\cos \left(2 \cdot \pi \cdot \mathrm{f}_{\mathrm{i}} \cdot \mathrm{t}^{\prime}{ }_{\text {ch_ini }}\right)-\cos \left(2 \cdot \pi \cdot \mathrm{f}_{\mathrm{i}} \cdot \mathrm{t}^{\prime}\right)\right)}{\mathrm{r}_{\mathrm{tr}_{\mathrm{i}}} \cdot \mathrm{L}_{\mathrm{Lk}_{-} \mathrm{i}} \cdot \pi^{2} \cdot \mathrm{f}_{\mathrm{i}}}+ \\
& +\frac{\left(\mathrm{V}_{\text {cell_ } \mathrm{i}}+\mathrm{V}_{\mathrm{knee}}\right) \cdot\left(\mathrm{t}_{\left.{ }_{\text {ch_ini }}{ }_{\text {ini }}-\mathrm{t}^{\prime}\right)}\right)}{\mathrm{r}_{\mathrm{tr} \_\mathrm{i}}^{2} \mathrm{i}} \cdot\left(\frac{1}{\mathrm{~L}_{\mathrm{Lk}_{-} \mathrm{i}}}+\frac{1}{\mathrm{~L}_{\mathrm{m}_{-} \mathrm{i}}}\right)
\end{aligned}
$$

Considering this equation and (16), the maximum average current injected into the cell can be defined as:

$$
I_{\text {cell_i_max }}=f_{i} \cdot \int_{t_{\text {ch__nini }}^{\prime}}^{t_{\text {ch_end }}^{\prime}} i_{\text {cell__ } i_{-} \max }\left(t^{\prime}\right) \cdot d t^{\prime} \text {. }
$$

Defining $\mathrm{L}_{\mathrm{p}_{-} \mathrm{i}}$ as the parallel connection of $\mathrm{L}_{\mathrm{Lk}_{-} \mathrm{i}}$ and $\mathrm{L}_{\mathrm{m}_{-} \mathrm{i}}$, and $\lambda_{\mathrm{i}}$ as:

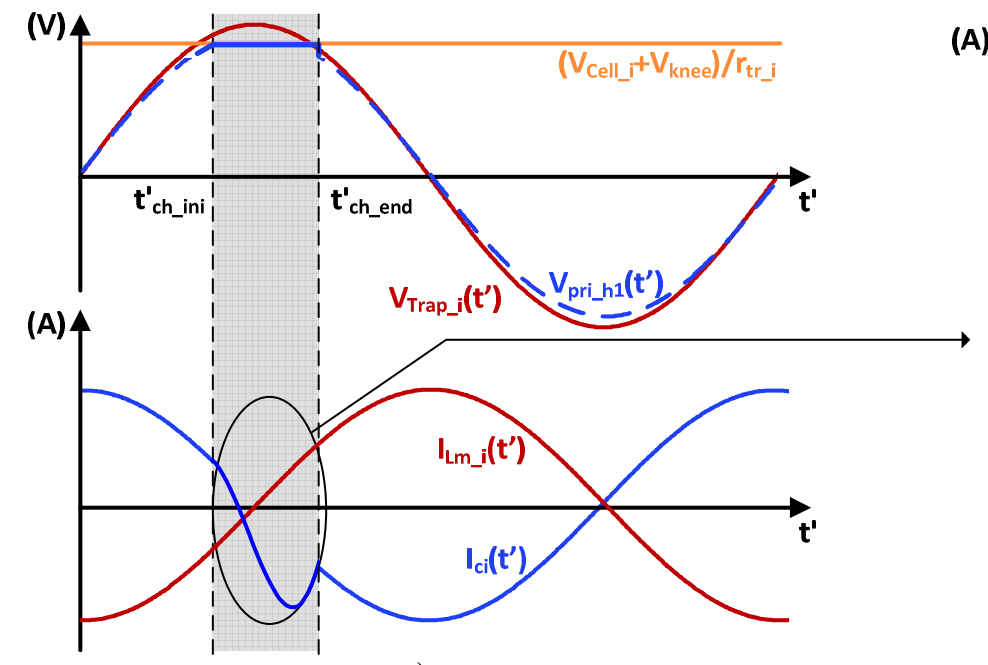

a)

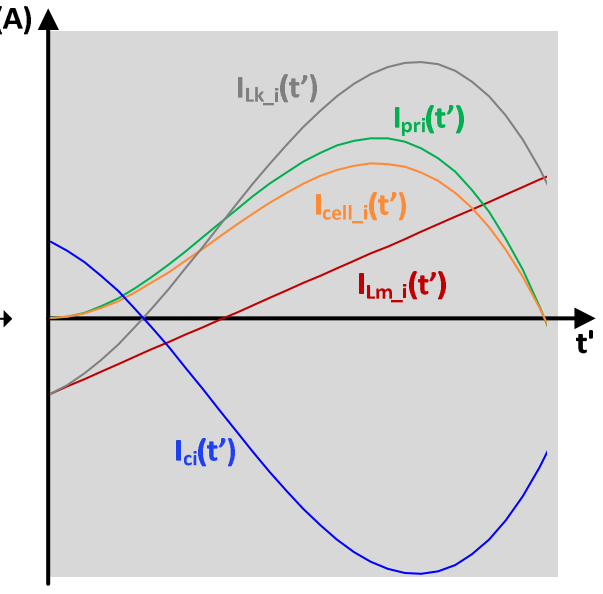

Fig. 4. a) Main voltages and currents; b) detail of the currents between $t^{\prime}{ }_{\text {ch_ini }}$ and $t^{\prime}$ ch_end. 


$$
\lambda_{\mathrm{i}}=\frac{\mathrm{L}_{\mathrm{Lk}_{-} \mathrm{i}}}{\mathrm{L}_{\mathrm{p}_{-} \mathrm{i}}}=\frac{\mathrm{L}_{\mathrm{m}_{-} \mathrm{i}}+\mathrm{L}_{\mathrm{Lk}_{-} \mathrm{i}}}{\mathrm{L}_{\mathrm{m}_{-} \mathrm{i}}}
$$

equation (17) becomes:

$$
\begin{aligned}
& \mathrm{i}_{\text {cell_i_max }}\left(\mathrm{t}^{\prime}\right)= \\
& =\frac{1}{\mathrm{r}_{\mathrm{tr}_{-} \mathrm{i}}^{2} \cdot 2 \cdot \pi \cdot \mathrm{f}_{\mathrm{i}} \cdot \mathrm{L}_{\mathrm{Lk}_{-} \mathrm{i}}} \text {. } \\
& {\left[\frac{2 \cdot r_{\text {tr }_{-} i} \cdot V_{\text {in }} \cdot\left(\cos \left(2 \cdot \pi \cdot f_{i} \cdot t^{\prime}{ }_{\text {ch_ini }}\right)-\cos \left(2 \cdot \pi \cdot f_{i} \cdot t^{\prime}\right)\right)}{\pi}+\right.\text {. }} \\
& \left.+2 \cdot \pi \cdot f_{i} \cdot \lambda_{i} \cdot\left(V_{\text {cell_i }}+V_{\text {knee }}\right) \cdot\left(t^{\prime}{ }_{\text {ch_ini }}-t^{\prime}\right)\right]
\end{aligned}
$$

Also, defining the parameters $\mu_{\mathrm{i}}, \varphi_{\mathrm{i}}, \varphi_{\text {ini }}$ and $\varphi_{\text {end }}$ as:

$$
\begin{gathered}
\mu_{\mathrm{i}}=\frac{\mathrm{V}_{\text {cell_i }}+\mathrm{V}_{\text {knee }}}{\mathrm{V}_{\text {in }}}, \\
\varphi_{\mathrm{i}}=2 \cdot \pi \cdot \mathrm{f}_{\mathrm{i}} \cdot \mathrm{t}^{\prime}, \\
\varphi_{\text {ini }}=2 \cdot \pi \cdot \mathrm{f}_{\mathrm{i}} \cdot \mathrm{t}^{\prime}{ }_{\text {ch_ini }}, \\
\varphi_{\text {end }}=2 \cdot \pi \cdot \mathrm{f}_{\mathrm{i}} \cdot \mathrm{t}_{\text {ch_end }}^{\prime},
\end{gathered}
$$

equation (20) becomes:

$$
\begin{aligned}
& \mathrm{i}_{\text {cell_i } \mathrm{i}_{\text {max }}}\left(\mathrm{t}^{\prime}\right)= \\
& =\frac{\mathrm{V}_{\mathrm{in}}}{\mathrm{r}_{\mathrm{tr} \_\mathrm{i}}^{2} \cdot 2 \cdot \pi \cdot \mathrm{f}_{\mathrm{i}} \cdot \mathrm{L}_{\mathrm{Lk}_{-} \mathrm{i}}} . \\
& {\left[\frac{2 \cdot \mathrm{r}_{\mathrm{tr} \mathrm{i}_{\mathrm{i}}} \cdot\left(\cos \varphi_{\mathrm{ini}}-\cos \varphi_{\mathrm{i}}\right)}{\pi}+\lambda_{\mathrm{i}} \cdot \mu_{\mathrm{i}} \cdot\left(\varphi_{\text {ini }}-\varphi_{\mathrm{i}}\right)\right]}
\end{aligned}
$$

This equation can be normalized by dividing $\mathrm{i}_{\text {cell___max }}\left(\mathrm{t}^{\prime}\right)$ by the base current $\mathrm{I}_{\text {base }_{-}}$:

$$
I_{\text {base }_{-} \mathrm{i}}=\frac{\mathrm{V}_{\text {in }}}{2 \cdot \pi \cdot f_{\mathrm{i}} \cdot \mathrm{L}_{\mathrm{Lk}_{-} \mathrm{i}}},
$$

obtaining:

$$
\begin{aligned}
& \gamma_{\mathrm{i}}=\frac{\mathrm{i}_{\text {cell_ } \mathrm{i}_{\text {} \max }}\left(\mathrm{t}^{\prime}\right)}{\mathrm{I}_{\text {base }_{-} \mathrm{i}}}= \\
& =\frac{1}{\mathrm{r}_{\mathrm{tr} \_\mathrm{i}}^{2}} \cdot\left[\frac{2 \cdot \mathrm{r}_{\mathrm{tr} \mathrm{i}_{\mathrm{i}}} \cdot\left(\cos \varphi_{\text {ini }}-\cos \varphi_{\mathrm{i}}\right)}{\pi}+\lambda_{\mathrm{i}} \cdot \mu_{\mathrm{i}} \cdot\left(\varphi_{\mathrm{ini}}-\varphi_{\mathrm{i}}\right)\right] .
\end{aligned}
$$

From (12), (23) becomes:

$$
\varphi_{\text {ini }}=\operatorname{asin}\left(\frac{\mu_{\mathrm{i}} \cdot \lambda_{\mathrm{i}}}{\mathrm{r}_{\mathrm{tr}_{-} \mathrm{i}}} \cdot \frac{\pi}{2}\right),
$$

Similarly, $\varphi_{\text {end }}$ can be obtained by making $\gamma_{i}$ equal to zero and solving:

$$
\cos \varphi_{\text {ini }}-\cos \varphi_{\text {end }}=\frac{\mu_{\mathrm{i}} \cdot \lambda_{\mathrm{i}}}{\mathrm{r}_{\mathrm{tr}_{-} \mathrm{i}}} \cdot \frac{\pi}{2} \cdot\left(\varphi_{\mathrm{end}}-\varphi_{\mathrm{ini}}\right)
$$

Once $\varphi_{\text {end }}$ is obtained, the conduction angle $\Delta \varphi_{c}$ can be easily obtained:

$$
\Delta \varphi_{\mathrm{c}}=\varphi_{\mathrm{end}}-\varphi_{\mathrm{ini}}
$$

The normalized maximum average current injected into the cell is:

$$
\Gamma_{\mathrm{i}}=\frac{\mathrm{I}_{\text {cell__i_max }}}{\mathrm{I}_{\text {base_i }}}=\frac{1}{2 \cdot \pi} \cdot \int_{\varphi_{\text {ini }}}^{\varphi_{\text {end }}} \gamma_{\mathrm{i}}\left(\varphi_{\mathrm{i}}\right) \cdot \mathrm{d} \varphi_{\mathrm{i}}
$$

It should be taken into account that the magnetizing inductance of the transformer is considerably higher than its leakage inductance. Therefore, (19) becomes:

$$
\lambda_{\mathrm{i}} \approx 1
$$

and hence, (12), (27), (28) and (29) become:

$$
\begin{aligned}
& \mathrm{t}_{\mathrm{ch}_{-} \mathrm{ini}}^{\prime} \approx \frac{1}{2 \cdot \pi \cdot \mathrm{f}_{\mathrm{i}}} \cdot \operatorname{asin}\left(\frac{\mathrm{V}_{\mathrm{cell}_{-} \mathrm{i}}+\mathrm{V}_{\mathrm{knee}}}{\mathrm{r}_{\mathrm{tr}_{-} \mathrm{i}}} \cdot \frac{\pi}{2 \cdot \mathrm{V}_{\mathrm{in}} \cdot \sin (\pi \cdot \mathrm{D})}\right) \text {. } \\
& \gamma_{\mathrm{i}} \approx \frac{1}{\mathrm{r}_{\mathrm{tr} \_}^{2} \mathrm{i}} \cdot\left[\frac{2 \cdot \mathrm{r}_{\mathrm{tr} \_\mathrm{i}} \cdot\left(\cos \varphi_{\mathrm{ini}}-\cos \varphi_{\mathrm{i}}\right)}{\pi}+\mu_{\mathrm{i}} \cdot\left(\varphi_{\mathrm{ini}}-\varphi_{\mathrm{i}}\right)\right] \text {. } \\
& \varphi_{\text {ini }} \approx \mathrm{a} \sin \left(\frac{\mu_{\mathrm{i}}}{\mathrm{r}_{\mathrm{tr} \_\mathrm{i}}} \cdot \frac{\pi}{2}\right) . \\
& \cos \varphi_{\text {ini }}-\cos \varphi_{\text {end }} \approx \frac{\mu_{\mathrm{i}}}{\mathrm{r}_{\mathrm{tr} \_\mathrm{i}}} \cdot \frac{\pi}{2} \cdot\left(\varphi_{\text {end }}-\varphi_{\text {ini }}\right)
\end{aligned}
$$

For the sake of simplicity, it can be considered that the voltage of all the cells is nearly the same (i.e., $\mathrm{V}_{\text {cell }} \approx \mathrm{V}_{\text {cell }}$ ) because the voltage imbalance is usually small in comparison to the voltage of the cells. Also, the input voltage of the halfbridge structure is the voltage of the cell pack. Therefore, $\mathrm{V}_{\text {in }} \approx \mathrm{V}_{\text {cell }} \cdot \mathrm{n}_{\text {cell }}, \mathrm{n}_{\text {cell }}$ being the number of cells connected in series. As a consequence, equation (21) becomes:

$$
\mu_{\mathrm{i}}=\frac{1+v_{\mathrm{knee}}}{\mathrm{n}_{\text {cell }}},
$$

where $v_{\text {knee }}$ is:

$$
v_{\text {knee }}=\frac{\mathrm{V}_{\text {knee }}}{\mathrm{V}_{\text {cell }}} .
$$

The evolution of the conduction angle $\Delta \varphi_{\mathrm{c}}$ as a function of the turns ratio $\mathrm{r}_{\text {tr_i }}$ for different number of cells $\left(\mathrm{n}_{\text {cell }}\right)$ and for different values of $v_{\text {knee }}$ can be computed from (30), (35), the solution of (36), and (37). Fig. 5 shows the results obtained for values of $n_{\text {cell }}$ around 4 , which will be used in section IV.B and section V.

In the same way, $\Gamma_{\mathrm{i}}$ can be also expressed as a function of $\mathrm{r}_{\text {tr } \mathrm{i}}, \mathrm{n}_{\text {cell }}$, and $v_{\text {knee. }}$. The results are given in Fig. 6 .

\section{DESIGN GUIDELINE}

In the design of the proposed trap-based equalizer it is mandatory to take into account several issues.

\section{A. Influence of tolerances}

For a given trap, the nominal resonant frequency is defined by (2). For this analysis, it has been assumed that the resonant frequency of trap $\mathrm{i}$ is lower than the resonant frequency of trap $i+1$ : 

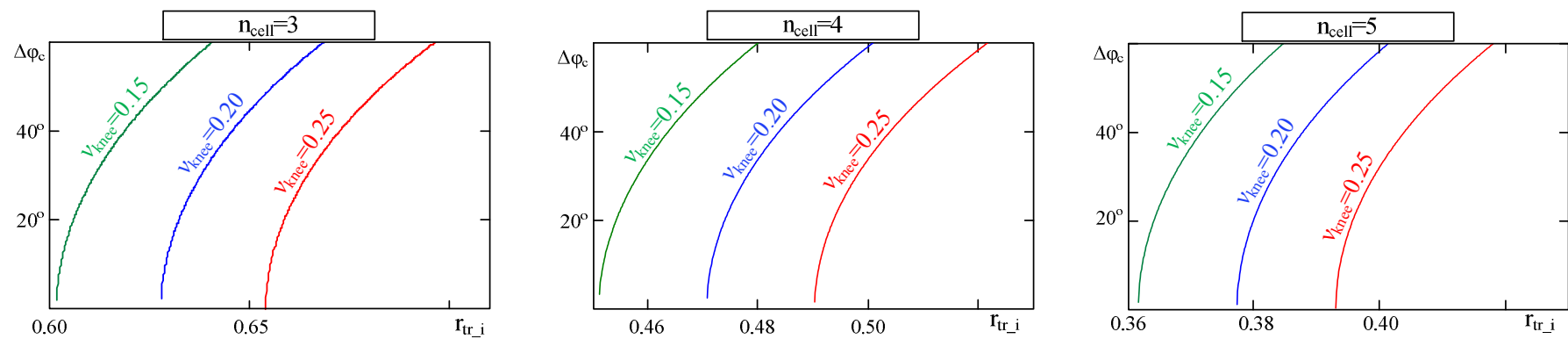

Fig. 5. Conduction angle as a function of $\mathrm{r}_{\text {tr i }}$ for values of $\mathrm{n}_{\text {cell }}$ around four, which is the number of cells used in the experimental results.
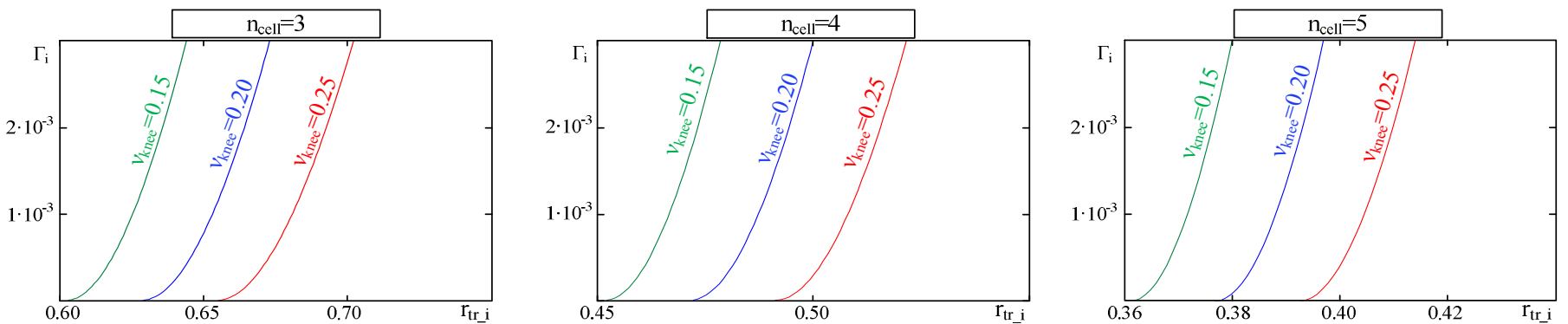

Fig. 6. Normalized maximum average current as a function of the turns ratio for values of $\mathrm{n}_{\text {cell }}$ around four.

$$
f_{i}<f_{i+1} .
$$

The actual resonant frequency of any trap will be inside a range defined by the tolerances of its inductor and its capacitor. Its resonant frequency may be as low as:

$$
\begin{aligned}
f_{\text {min_i }} & =\frac{1}{2 \cdot \pi \cdot \sqrt{L_{i} \cdot\left(1+\operatorname{tol}_{L}\right) \cdot C_{i} \cdot\left(1+\operatorname{tol}_{C}\right)}}= \\
& =\frac{f_{i}}{\sqrt{\left(1+\text { tol }_{L}\right) \cdot\left(1+\text { tol }_{C}\right)}}
\end{aligned}
$$

where tol $l_{L}$ and tol $l_{C}$ are the tolerances of the inductor and the capacitor of the trap. Its maximum resonant frequency due to tolerances is:

$$
\begin{aligned}
f_{\text {max }_{\_}} & =\frac{1}{2 \cdot \pi \cdot \sqrt{L_{i} \cdot\left(1-\text { tol }_{L}\right) \cdot C_{i} \cdot\left(1-\text { tol }_{C}\right)}}= \\
& =\frac{f_{i}}{\sqrt{\left(1-\text { tol }_{L}\right) \cdot\left(1-\text { tol }_{C}\right)}}
\end{aligned}
$$

The proposed equalizer would work properly even when the resonant frequencies of the traps were not exactly equal to the theoretical ones as long as their relative positions were not affected. If this condition is introduced in the design process, then the resulting system is robust and is not negatively affected by tolerances. The mathematical expression of this condition is:

$$
\begin{aligned}
& \mathrm{f}_{\text {max }_{-} \mathrm{i}}<\mathrm{f}_{\text {min }_{-}{ }_{i+1}} \Rightarrow \\
& \Rightarrow \frac{\mathrm{f}_{\mathrm{i}}}{\sqrt{\left(1-\mathrm{tol}_{\mathrm{L}}\right) \cdot\left(1-\mathrm{tol}_{\mathrm{C}}\right)}}<\frac{\mathrm{f}_{\mathrm{i}+1}}{\sqrt{\left(1+\mathrm{tol}_{\mathrm{L}}\right) \cdot\left(1+\text { tol }_{\mathrm{C}}\right)}} .
\end{aligned}
$$

Therefore:

$$
f_{i+1}>\sqrt{\frac{\left(1+\operatorname{tol}_{L}\right) \cdot\left(1+\text { tol }_{C}\right)}{\left(1-\text { tol }_{L}\right) \cdot\left(1-\text { tol }_{C}\right)}} \cdot f_{i}=\tau_{\text {tol }} \cdot f_{i}
$$

where $\tau_{\text {tol }}$ is defined by the tolerances of the trap's components. of $f_{1}$ :

The design should start by choosing the minimum value

$$
f_{\text {min }_{-} 1}=\frac{1}{2 \cdot \pi \cdot \sqrt{\mathrm{L}_{1} \cdot \mathrm{C}_{1}}} \cdot \frac{1}{\sqrt{\left(1+\text { tol }_{\mathrm{L}}\right) \cdot\left(1+\text { tol }_{\mathrm{C}}\right)}},
$$

So,

$$
\mathrm{L}_{1} \cdot \mathrm{C}_{1}=\frac{1}{\left(2 \cdot \pi \cdot \mathrm{f}_{\text {min_1 }_{1}}\right)^{2}} \cdot \frac{1}{\left(1+\operatorname{tol}_{\mathrm{L}}\right) \cdot\left(1+\operatorname{tol}_{\mathrm{C}}\right)} .
$$

Once the product $\mathrm{L}_{1} \cdot \mathrm{C}_{1}$ of the first trap is obtained, it is possible to follow an iterative process in which (43) is used to calculate the $\mathrm{L} \cdot \mathrm{C}$ product of the next trap based on the $\mathrm{L} \cdot \mathrm{C}$ product of the previous one.

\section{B. Calculation of the inductance, the capacitance and the turns ratio of each trap}

There are infinite solutions for designing each trap as only the corresponding $\mathrm{L}_{\mathrm{i}} \cdot \mathrm{C}_{\mathrm{i}}$ value has been obtained in section IV.A. Nevertheless, it is possible to optimize the design of the proposed equalizer considering additional conditions which will lead to specific values of the capacitance and the inductance of each trap.

The specific impedance $Z_{i}$ of each trap can be defined as:

$$
Z_{i}=\sqrt{\frac{L_{i}}{C_{i}}}
$$

The resonant current driven by the inductor of the chosen trap was defined in (9). Considering this equation, (2) and (46):

$$
\mathrm{i}_{\mathrm{Lm}_{-} \mathrm{i}}\left(\mathrm{t}^{\prime}\right)=\mathrm{i}_{\mathrm{Lk}_{-} \mathrm{i}}\left(\mathrm{t}^{\prime}\right)=\frac{\mathrm{A}_{\mathrm{h1}}\left(\mathrm{D}, \mathrm{V}_{\mathrm{in}}\right)}{\mathrm{Z}_{\mathrm{i}}} \cdot \sin \left(2 \cdot \pi \cdot \mathrm{f}_{\mathrm{i}} \cdot \mathrm{t}^{\prime}-\frac{\pi}{2}\right)
$$


In the same way, the current driven by the capacitor (defined in (11)) is:

$$
\mathrm{i}_{\mathrm{Ci}}\left(\mathrm{t}^{\prime}\right)=\frac{\mathrm{A}_{\mathrm{h} 1}\left(\mathrm{D}, \mathrm{V}_{\mathrm{in}}\right)}{\mathrm{Z}_{\mathrm{i}}} \cdot \sin \left(2 \cdot \pi \cdot \mathrm{f}_{\mathrm{i}} \cdot \mathrm{t}^{\prime}+\frac{\pi}{2}\right) \text {. }
$$

Considering $\mathrm{D}=0.5$, (47) and (48) becomes:

$$
\begin{gathered}
\mathrm{i}_{\mathrm{Lm}_{-} \mathrm{i}_{-} \max }\left(\mathrm{t}^{\prime}\right)=\mathrm{i}_{\mathrm{Lk}_{-} \mathrm{i}_{-} \max }\left(\mathrm{t}^{\prime}\right)=\frac{2 \cdot \mathrm{V}_{\text {in }}}{\mathrm{Z}_{\mathrm{i}} \cdot \pi} \cdot \sin \left(2 \cdot \pi \cdot \mathrm{f}_{\mathrm{i}} \cdot \mathrm{t}^{\prime}-\frac{\pi}{2}\right), \\
\mathrm{i}_{\mathrm{Ci}_{-} \max }\left(\mathrm{t}^{\prime}\right)=\frac{2 \cdot \mathrm{V}_{\text {in }}}{\mathrm{Z}_{\mathrm{i}} \cdot \pi} \cdot \sin \left(2 \cdot \pi \cdot \mathrm{f}_{\mathrm{i}} \cdot \mathrm{t}^{\prime}+\frac{\pi}{2}\right) .
\end{gathered}
$$

The ratio between the energy in the resonant circuit (i.e., chosen trap) and the energy injected into the chosen cell during each switching period is denoted by $\mathrm{Q}_{\mathrm{E}_{-} \mathrm{i}}$ and can be defined as:

$$
\mathrm{Q}_{\mathrm{E}_{-} \mathrm{i}}=\frac{\mathrm{E}_{\text {res_i }}}{\mathrm{E}_{\text {cell__i}},}
$$

where $E_{\text {res } i}$ is the energy in the resonant circuit and $E_{\text {cell } i}$ the energy injected into the cell. If the amount of energy injected into the cell is lower than the amount of resonant energy that the chosen trap is handling, then the behavior of the string of traps will not depend on whether the diode is reverse biased or not. This means that the voltage across the capacitor of the trap will be sinusoidal even during the short periods of time when the diode is conducting. Hence, it is interesting to design the system with values of $\mathrm{Q}_{\mathrm{E}_{\mathrm{i}}}$ higher than unity so that the behavior of the trap is not affected by the cell (see later in this section).

The resonant energy in the chosen trap can be obtained from its voltage and the value of its capacitor (when the voltage in the trap is the peak one, the energy in the inductor is zero):

$$
\mathrm{E}_{\text {res_i }}=\mathrm{C}_{\mathrm{i}} \cdot \frac{2 \cdot \mathrm{V}_{\text {in }}^{2}}{\pi^{2}} .
$$

The energy injected into the cell in each switching period can be denoted as:

$$
\mathrm{E}_{\text {cell_i }}=\frac{\mathrm{I}_{\text {cell__ } \mathrm{i}_{\text {max }}} \cdot \mathrm{V}_{\text {cell__i }}}{\mathrm{f}_{\mathrm{i}}} \text {. }
$$

Hence,

$$
\mathrm{Q}_{\mathrm{E}_{-} \mathrm{i}}=\frac{2 \cdot \mathrm{f}_{\mathrm{i}} \cdot \mathrm{C}_{\mathrm{i}} \cdot \mathrm{V}_{\text {in }}^{2}}{\pi^{2} \cdot \mathrm{V}_{\text {cell_ }} \cdot \mathrm{I}_{\text {cell_ } \mathrm{i}_{-} \max }} .
$$

Taking into account (2) and (46), then (54) becomes:

$$
\mathrm{Q}_{\mathrm{E}_{-} \mathrm{i}}=\frac{\mathrm{V}_{\text {in }}^{2}}{\pi^{3} \cdot \mathrm{Z}_{\mathrm{i}} \cdot \mathrm{V}_{\text {cell_i } \mathrm{i}} \cdot \mathrm{I}_{\text {cell__ } \mathrm{i}_{-} \max }} \text {. }
$$

Fig. 7 shows the waveforms corresponding to the voltage across the resonant capacitors and the current injected into

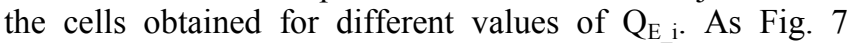
shows, the voltage across the capacitor can be considered sinusoidal when the value of $\mathrm{Q}_{\mathrm{E} i}$ is higher than two. However, very high values of $\mathrm{Q}_{\mathrm{E}_{\mathrm{i}}}$ lead to high circulating currents through the resonant capacitor and inductor, as can be deduced from (49), (50) and (55). As a consequence, a tradeoff must be met when choosing the values of $\mathrm{Q}_{\mathrm{E}_{\mathrm{i}}}$ in order to obtain a system in which efficiency is not excessively affected while the voltage across the resonant capacitor can be considered sinusoidal even when the diode is directly biased. Values of $\mathrm{Q}_{\mathrm{E}_{-} \mathrm{i}}$ around two (or slightly higher) can be considered good options. In fact, $\mathrm{Q}_{\mathrm{E}}$ i can be designed to be lower than two (as in Fig. 7a or Fig. 7b). Nevertheless, in such a case, the voltage is excessively distorted and the behavior of the system cannot be predicted by the proposed equations.

With (19), (31), (37) and (38), equation (55) can be rewritten as:

$$
\mathrm{Q}_{\mathrm{E}_{-} \mathrm{i}}=\frac{1}{\pi^{2}} \cdot \frac{\lambda_{\mathrm{i}}-1}{\lambda_{\mathrm{i}}} \cdot \frac{1}{\left(\mu_{\mathrm{i}}-v_{\text {knee }}\right) \cdot \Gamma_{\mathrm{i}}},
$$

which will be used in the design guideline.

The calculation of the precise values of $\mathrm{L}_{\mathrm{i}}$ and $\mathrm{C}_{\mathrm{i}}$ should be made as follows. First of all, the value of $v_{\text {knee }}$ can be calculated using (38). With $v_{\text {knee }}$ and the number of cells, $\mathrm{n}_{\text {cell, }}$, the value of $\mu \mathrm{i}$ can be then obtained from (37). Choosing a reasonable value for the conduction angle $\Delta \varphi_{\mathrm{c}}$ (i.e., around $30^{\circ}$ ), and with $\mu \mathrm{i}$, it is possible to obtain the value of the turns ratio of the transformers, $r_{\text {tr } i}$, by means of equations (30), (35) and (36). In Fig. 5, equation (30) is graphically represented: the conduction angle is depicted as a function of $r_{\text {tr i }}$ for different values of $n_{\text {cell }}$ and $v_{\text {knee }}$ (both

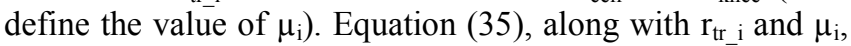
can be used to obtain the value of $\varphi_{\text {ini }}$ and, consequently, the value of $\varphi_{\text {end }}$ according to the chosen value of $\Delta \varphi_{\mathrm{c}} . \Gamma_{\mathrm{i}}$ can be calculated using $\varphi_{\text {ini }}, \varphi_{\text {end }}, r_{\text {tr }}, \mu_{\mathrm{i}}$ and equations (31) and (34). This has been graphically represented in Fig. 6. As has been explained, the value of $\mathrm{Q}_{\mathrm{E}}$ i should be high enough in order to assure the proper operation of the resonant traps (as can be seen in Fig. 7, any value of $\mathrm{Q}_{\mathrm{E}_{\mathrm{i}}}$ higher than 2 will lead to
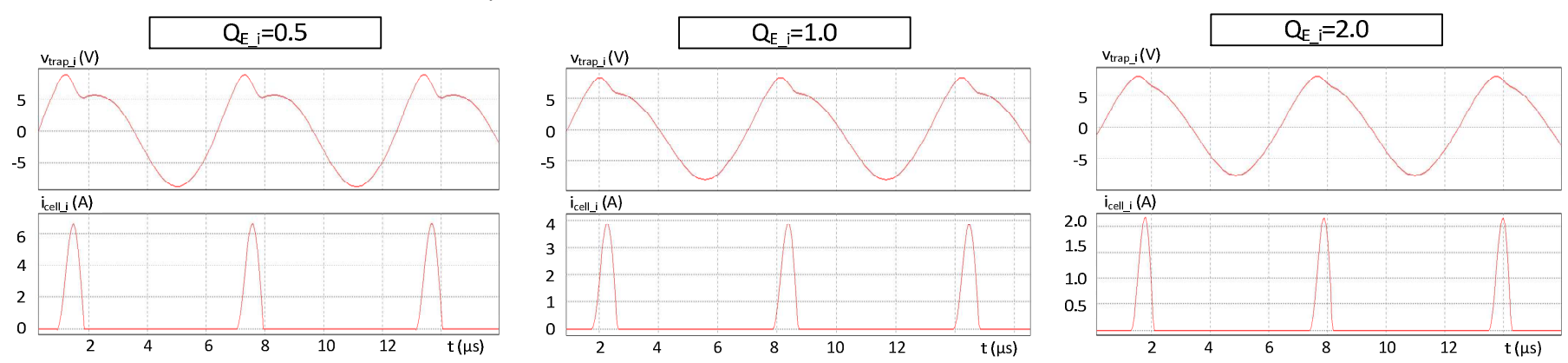

Fig. 7. Trap voltage and cell current for different values of $\mathrm{Q}_{E}$ i. The distortion in the trap voltage depends on this parameter. 
satisfactory results). Therefore, once $\Gamma_{\mathrm{i}}$ is obtained, equation (56) can be used to determine the minimum value of $\lambda_{i}$ for the chosen value of $Q_{E}$. This minimum value of $\lambda_{i}$ (see equation (19)), should be lower than the value of $\lambda_{i}$ presented by any of the transformers of the traps once they are built. $I_{\text {cell } \mathrm{i} \max }$, the maximum average equalizing current, is a parameter defined by the designer. Therefore, if the value of $\lambda_{\mathrm{i}}$ is satisfactory (i.e., low enough), then equation (55) can be used to obtained the value of $Z_{i}$ according to the chosen value of $\mathrm{Q}_{\mathrm{E}}$. With $\mathrm{Z}_{\mathrm{i}}$ (equation (46)) and fi (its calculation was presented in section IV.A), it is possible to obtain the required values of $\mathrm{L}_{\mathrm{i}}$ and $\mathrm{C}_{\mathrm{i}}$.

\section{Design of the magnetics}

The switching frequency of the proposed system is variable but, ideally, each inductor is going to withstand appreciable voltage only at a frequency equal to the resonant frequency of the trap it belongs to. When the switching frequency of the system is different from the resonant frequency of a trap, the voltage across that trap is almost zero and, consequently, its inductor current is almost zero as well. This means that each inductor does not have to be designed for the whole frequency range, but only for the resonant frequency of its trap.

\section{EXPERIMENTAL RESULTS}

A prototype has been built following the design guideline and with the purpose of validating it. It has been designed for a pack of four cells connected in series. The switching frequency range is $100 \mathrm{kHz}-215 \mathrm{kHz}$ considering tolerances of $7.5 \%$ in both, inductors and capacitors (see Table 1). The value of each resonant frequency $f_{i}$ has been obtained according to the design process described in section IV.A. The value of $v_{\text {knee }}$ is around 0.2 ; therefore, $\mu_{\mathrm{i}}$ is 0.3 . As can be seen in Fig. 5, for a conduction angle of around $30^{\circ}$, the required turns ratio is 0.48 . It may advisable to increase this value so that even due to tolerances, the RDSON of the MOSFETs, the influence of other traps, etc. the required voltage in the secondary side of the transformer is reached. From Fig. 6 (or the corresponding equations), the resulting value of $\Gamma_{\mathrm{i}}$ is around $2 \cdot 10-3$. As a consequence, the required minimum value of $\lambda_{\mathrm{i}}$ is 1.009 for $\mathrm{Q}_{\mathrm{E}_{-}}=5$ (higher than 2 , the

Table 1. Minimum, nominal and maximum resonant frequency of each trap. Nominal values of inductance and capacitance.

\begin{tabular}{|c|c|c|c|c|c|}
\hline TRAP & $\mathbf{f}_{\text {nom }}(\mathbf{k H z})$ & $\mathbf{f}_{\min }(\mathbf{k H z})$ & $\mathbf{f}_{\max }(\mathbf{k H z})$ & $\mathbf{L}(\boldsymbol{\mu H})$ & $\mathbf{C}(\boldsymbol{\mu F})$ \\
\hline 1 & 109 & 101 & 117 & 6.22 & 0.34 \\
\hline 2 & 134 & 124 & 145 & 5.09 & 0.28 \\
\hline 3 & 164 & 152 & 177 & 4.16 & 0.23 \\
\hline 4 & 200 & 186 & 215 & 3.40 & 0.18 \\
\hline
\end{tabular}

minimum value shown in Fig. 7). This value of $\lambda_{i}$ is lower than the real value that any transformer normally has.

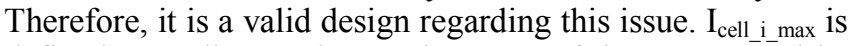
defined according to the requirements of the system and its value is $0.1 \mathrm{~A}$. Consequently, the value of $Z_{i}$ should be close to 4 . With $Z_{i}$ and $f_{i}$, it is possible to obtain the values of $L_{i}$ and $\mathrm{C}_{\mathrm{i}}$ (see Table 1$)$.

In Fig. 8, $\mathrm{V}_{\text {string, }}$, the voltage withstood by string of traps, and $\mathrm{V}_{\text {trap_3 }}$, the voltage withstood by the chosen trap (in this case, trap 3), are shown for three different values of $D$ but for the same value of switching frequency $(166 \mathrm{kHz}$ in order to choose trap 3). As can be seen, the proposed system can determine the amplitude of the voltage withstood by the chosen trap by means of the duty cycle. This implies that the charging process (final voltage of the cell, equalization current, etc.) can be perfectly controlled.

In Fig. 9, the secondary-side voltage of the transformer implemented in trap $3\left(\mathrm{~V}_{\text {sec } 3}\right)$, the voltage of cell $3\left(\mathrm{~V}_{\text {cell } 3}\right)$, the equalization current of this cell during a switching period $\left(\mathrm{I}_{\text {cell_3}}\right)$ and the voltage applied to trap $3\left(\mathrm{~V}_{\text {trap } 3} \cdot \mathrm{r}_{\text {tr }}\right.$, referred to the secondary side) are presented for three different duty cycles. As can be seen, the charging process is as described in section III. It should be noted that the diode is operating at zero-current switching.

In Fig. 10a, Fig. 10b and Fig. 10c, the proposed equalizer is connected to real 2.5-Ah lithium-ion battery cells. In Fig. $10 \mathrm{a}$, the operation of the proposed equalizer is presented when the voltage of each cell is close to their nominal value (around $3.3 \mathrm{~V}$ ). After 92 minutes, the voltage of the four cells is within the desired range and the half-bridge converter stops its operation (i.e., both MOSFETs are turned-off). After 150 minutes from the start of the equalization process, the voltage of the four cells is stabilized and the final imbalance is around $5 \mathrm{mV}$. It should be taken into account that using a simple estimation of the OCV of the cells as the criterion for defining which one has to be charged is not an optimum approach. More precise methods can be found in literature [11]-[13]. Nevertheless, the implementation of an optimum Battery Management System (BMS) is out of the scope of this paper.

In Fig. 10b a similar test is carried out, but in this case one of the cells has reached $3.6 \mathrm{~V}$ (i.e. the recommended charging voltage) while cell 2, 3 and 4 have a lower voltage (unbalanced operation of the battery charger). As in the previous case, the cell with the lowest voltage is considered under charged. The final imbalance, after the stabilization
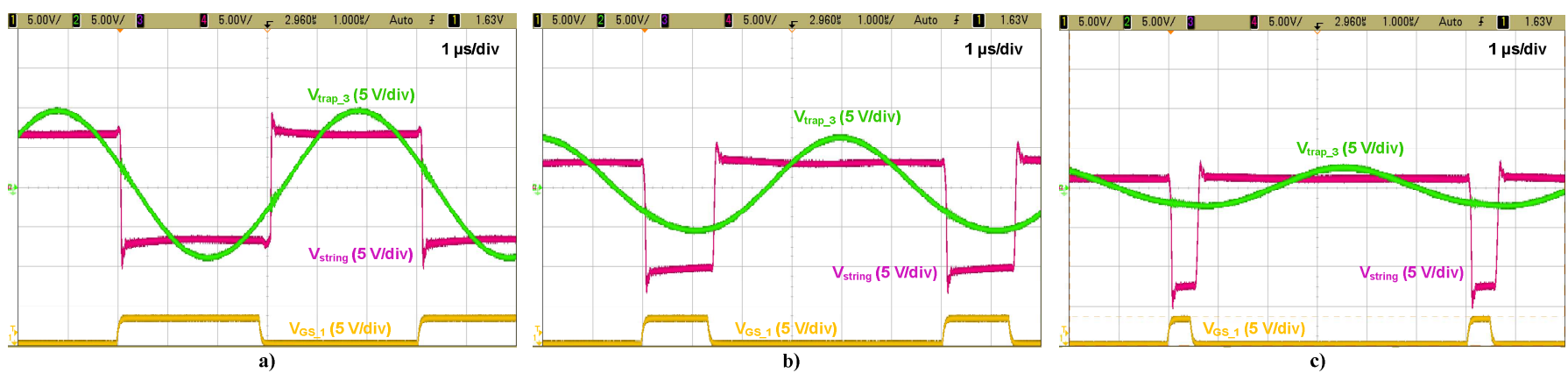

Fig. 8. Driving signal of MOSFET 1 , string voltage and trap 3 voltage for a) $D=50 \%, b) D=75 \%$ and c) $D=90 \%$ 

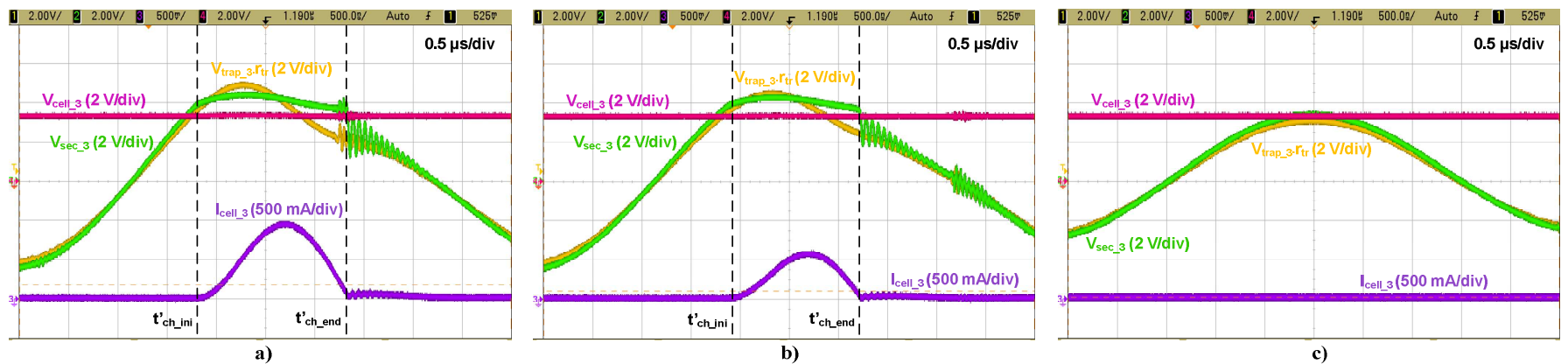

Fig. 9. Equalization current, cell 3 voltage and trap 3 voltage for three different charging rates. a) $D=0.5$; $b) D=0.75$; c) $D=0.90$.

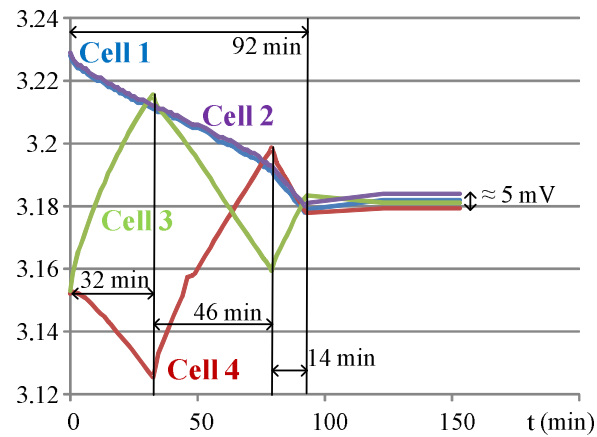

a)

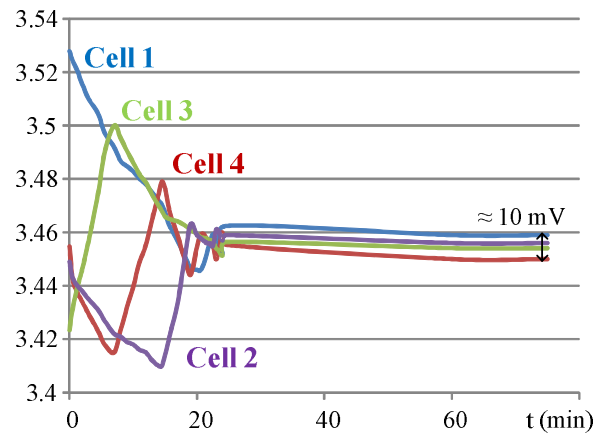

b)

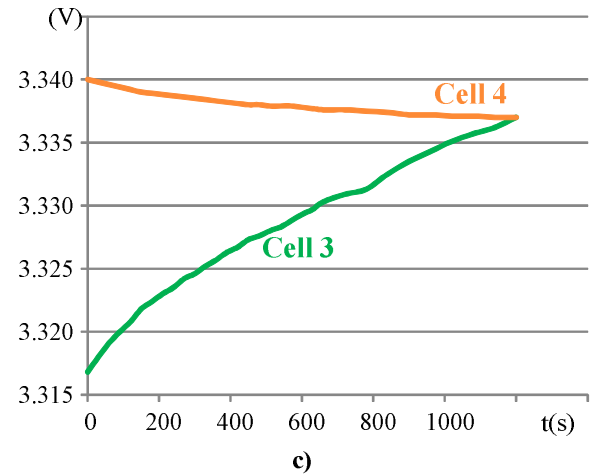

c)

Fig. 10. a) Operation of the proposed battery cell equalizer with different starting voltages for each cell; b) Operation of the proposed battery cell equalizer when one of the cells has reached the maximum value; c) Detail of the charging process of one of the cells.

time (around 50 minutes), is close to $10 \mathrm{mV}$.

Finally, in Fig. 10c, a detail of the charging process of one of the cells is presented (the stabilization time is not shown).

\section{CONCLUSIONS}

In this paper, an optimized design guideline for equalizers based on the wave-trap concept has been presented.

The ratio between the resonant energy in the chosen trap and the energy injected into the corresponding cell is the key parameter. This ratio should be high enough to assure that the resonance in the trap is not affected by the injection of part of that energy into the cell. Also, this value should be low enough so that resonant energy does not lead to too-high losses and low efficiency. This ratio should have a value around unity in order to obtain a trade-off.

Also, tolerances in the components are important. Traps have to be located in such a way that variations in the switching frequency due to tolerances do not lead to the overlap of two adjacent traps.

\section{REFERENCES}

[1] M. Daowd, N. Omar, P. Van den Bossche, and J. Van Mierlo, "Passive and active battery balancing comparison based on MATLAB simulation," in Vehicle Power and Propulsion Conference (VPPC), 2011 IEEE, 2011, pp. 1-7.

[2] J. Cao, N. Schofield, and A. Emadi, "Battery balancing methods: A comprehensive review," in Vehicle Power and Propulsion Conference, 2008. VPPC '08. IEEE, 2008, pp. 1-6.

[3] T. A. Stuart and Z. Wei, "Fast equalization for large lithium ion batteries," Aerospace and Electronic Systems Magazine, IEEE, vol. 24, pp. 27-31, 2009.
[4] V. L. Teofilo, L. V. Merritt, and R. P. Hollandsworth, "Advanced lithium ion battery charger," Aerospace and Electronic Systems Magazine, IEEE, vol. 12, pp. 30-36, 1997.

[5] P. Sang-Hyun, K. Tae-Sung, P. Jin-Sik, M. Gun-Woo, and Y. Myung-Joong, "A New Buck-boost Type Battery Equalizer," in Applied Power Electronics Conference and Exposition, 2009. APEC 2009. Twenty-Fourth Annual IEEE, 2009, pp. 1246-1250.

[6] S. Jong-Won, S. Gab-Su, C. Chang-Yoon, and C. Bo-Hyung, "Selective flyback balancing circuit with improved balancing speed for series connected Lithium-ion batteries," in Power Electronics Conference (IPEC), 2010 International, 2010, pp. 1180-1184.

[7] M. Arias, D. Breton, M.M. Hernando, U. Viscarret, I. Gil, "Equalization system for serially-connected battery cells based on the wave-trap concept," Energy Conversion Congress and Exposition (ECCE), 2014 IEEE , vol., no., pp.4319,4326, 14-18 Sept. 2014

[8] F. Weiyi, F. C. Lee, P. Mattavelli, and H. Daocheng, "A Universal Adaptive Driving Scheme for Synchronous Rectification in LLC Resonant Converters," Power Electronics, IEEE Transactions on, vol. 27, pp. 3775-3781, 2012.

[9] F. Dianbo, L. Ya, F. C. Lee, and X. Ming, "A Novel Driving Scheme for Synchronous Rectifiers in LLC Resonant Converters," Power Electronics, IEEE Transactions on, vol. 24, pp. 1321-1329, 2009.

[10] Kazimierczuk, M.K.; Szaraniec, W., "Analysis of class E low di/dt rectifier with a series inductor," Aerospace and Electronic Systems, IEEE Transactions on, vol.29, no.1, pp.278,287, Jan 1993.

[11] Einhorn, M.; Roessler, W.; Fleig, J., "Improved Performance of Serially Connected Li-Ion Batteries With Active Cell Balancing in Electric Vehicles," Vehicular Technology, IEEE Transactions on , vol.60, no.6, pp.2448,2457, July 2011.

[12] Lezhang Liu; Le Yi Wang; Ziqiang Chen; Caisheng Wang; Feng Lin; Hongbin Wang, "Integrated System Identification and State-ofCharge Estimation of Battery Systems," Energy Conversion, IEEE Transactions on, vol.28, no.1, pp.12,23, March 2013.

[13] Xiaonan Lu; Kai Sun; Guerrero, J.M.; Vasquez, J.C.; Lipei Huang, "State-of-Charge Balance Using Adaptive Droop Control for Distributed Energy Storage Systems in DC Microgrid Applications," Industrial Electronics, IEEE Transactions on , vol.61, no.6, pp.2804,2815, June 2014 